\title{
RANCANG BANGUN APLIKASI MEDIA PEMBELAJARAN PENGENALAN RUPA DAN KARAKTER TOKOH WAYANG PURWA BERBASIS ANDROID I Gst Agung Alit Wismaya ${ }^{1}$, Made Sudarma ${ }^{2}$, I Made Arsa Suyadnya ${ }^{3}$ \\ 1,2,3 Jurusan Teknik Elektro, Fakultas Teknik, Universitas Udayana \\ Email :alitwismaya002@gmail.com ${ }^{1}, \underline{\text { msudarma@unud.ac.id }{ }^{2}}$, ${\text { arsa.suyadnya@unud.ac.id }{ }^{3}}$
}

\begin{abstract}
Abstrak
Sejarah masa lampau merupakan warisan dari para pendahulu yang seharusnya dijaga dan dilestarikan oleh para generasi muda berikutnya. Salah satunya adalah mahakarya yang terkenal dari Indonesia yaitu wayang purwa. Wayang purwa disebut juga wayang kulit karena terbuat dari kulit lembu. Wayang purwa sendiri biasanya menggunakan cerita Mahabharata dan Ramayana. Salah satu solusi yang dapat digunakan adalah mengimplementasikan wayang purwa dalam bentuk aplikasi media pembelajaran berbasis mobile. Aplikasi media pembelajaran dibangun untuk dapat dijalankan pada smartphone berbasis Android menggunakan software Unity yang mempunyai fitur 2D dengan user interface, drag and drop dan scripting bahasa pemrograman C\#. Aplikasi media pembelajaran wayang purwa memberikan pengetahuan tentang rupa dan karakter wayang purwa dalam bentuk game puzzle dan juga kuis. Berdasarkan hasil pengujian usability testing, memanfaatkan kuisioner terhadap 30 responden diperoleh hasil pada pengujian aspek grafis visual sebanyak $57 \%$ responden memberikan respon baik sedangkan pada pengujian aspek entertaintment dan pembelajaran sebanyak 90\% memberikan respon baik. Selain itu berdasarkan pengujian dengan menggunakan metode blackbox keseluruhan fungsionalitas aplikasi telah berjalan dengan baik. Dengan adanya aplikasi media pembelajaran ini diharapkan dapat meningkatkan minat para generasi muda untuk mempelajari wayang purwa.
\end{abstract}

Kata Kunci: Wayang Purwa, Mobile, Unity, Game, Android

\begin{abstract}
Past history is a legacy of its predecessor which should be maintained and preserved by the next younger generation. One of them is the famous masterpiece of Indonesia that is Wayang purwa. It is also called shadow puppets because it is made of calf leather. Wayang purwa itself usually uses the story of Mahabharata and Ramayana. One solution that can be used is implementing Wayang purwa in the form of mobile based learning media applications. Learning media applications are built to run on Android-based smart phones by using Unity software that features 2D with user interface, drag and drop and scripting $C$ \# programming languages. The application of wayang purwa learning media provides knowledge about the wayang or the puppet shadow's appearance and characters in the form of puzzle games as well as quizzes. Based on the results of usability testing by using questionnaires to 30 respondents, it was obtained the results on visual graphics aspect test that $57 \%$ of the respondents gave good response while in the aspect of entertainment and learning showed that $90 \%$ gave good response. In addition, based on the testing by using the black box method the overall functionality of the application has been running well. The learning media application is expected to increase the interest of the younger generation to learn wayang purwa.
\end{abstract}

Keywords: Wayang Purwa, Mobile, Unity, Game, Android

\section{PENDAHULUAN}

Saat ini, para generasi muda cenderung meniru budaya Barat dan sedikit demi sedikit meninggalkan unsur budaya Indonesia. Para generasi muda seharusnya menjaga dan me- lestarikan warisan budaya Indonesia, salah satunya adalah wayang purwa. Pada saat ini dengan semakin berkembangnya jaman banyak generasi muda telah melupakan dan 
hampir tidak mengetahui bagaimana karakteristik dan rupa dari wayang purwa.

Cara yang paling efektif untuk mengenalkan tentang rupa dan karakter dari tokoh wayang purwa adalah dengan membangun suatu media pembelajaran. Pada saat ini, perkembangan teknologi informasi yang pesat banyak dimanfaatkan untuk pengembangan pembelajaran. Beberapa penelitian yang telah dilakukan sebelumnya terkait pengembangan media pembelajaran berbasis teknologi informasi yang diantaranya "Pengembangan Game Edukasi Lingkungan Berbasis Android", pene-litian bertujuan untuk mengembangkan game edunvi pada perangkat berbasis Android dan mengetahui kinerja game pada perangkat berbasis Android dimana hasil dari penelitian ini adalah dapat dijadikan media edukasi tentang lingkungan pada anak-anak [1]. Selain itu "Rancang Bangun Aplikasi Game "Puzzle Kata", keunggulan dari aplikasi game tersebut adalah dapat membantu dalam memahami istilah-istilah yang ada pada teknologi informasi seperti jaringan komputer, internet, pengantar komputer dan struktur data [2]. Dan Rancang Bangun Aplikasi Edukasi "Ceria" Berbasis Android Media Pembelajaran untuk Anak Usia Dini. Tujuan dari penelitian tersebut adalah untuk membuat sebuah media pembelajaran yang disajikan berupa suara, dan video yang dapat memperkenalkan materi agar lebih menarik untuk diterima dan dipahami terutama pada anak-anak yang masih dalam usia dini agar dapat berpikir lebih aktif dan kreatif dimasa usia pertumbuhan [3]. Dalam pengenalan rupa dan tokoh wayang purwa dapat pula dikembangkan sebuah aplikasi pembelajaran yang menarik berbasis teknologi informasi.

Pada penelitian ini dibangun sebuah aplikasi yang berjudul Rancang Bangun Aplikasi Media Pembelajaran Pengenalan Rupa Dan Karakter Tokoh Wayang Purwa Berbasis Android, sebagai salah satu cara untuk memberikan media pembelajaran yang menarik tentang informasi rupa dan karakter pada aplikasi wayang purwa dimana dalam media pembelajaran tersebut berisi game puzzle, quiz, dan juga penjelasan dari wayang purwa, dengan adanya media pembelajaran tersebut, maka para generasi muda tidak harus membaca dari buku, tapi dengan hanya menggunakan gadget atau smarthphone.

\section{KAJIAN PUSTAKA}

Adapun yang akan dipaparkan pada tinjauan pustaka, yaitu landasan teori-teori yang menunjang penelitian.

\subsection{Wayang Purwa}

Wayang Purwa adalah wayang kulit yang ceritanya berasal dari kitab Mahabharata. Purwa yang artinya adalah awal, wayang purwa kira-kira mepunyai umur yang paling tua di antara wayang lainnya. Diperkirakan berita tentang wayang kulit purwa bisa dilihat dengan adanya prasasti di abad 11 di jaman pemerintahan Erlangga. Wayang kulit purwa biasanya mebawakan cerita Mahabharata serta Ramayana [4].

\subsection{Media Pembelajaran}

Terkait dengan media pembelajaran yaitu segala sesuatu yang dapat digunakan untuk menyampaikan suatu pesan dari pengirim pesan kepada penerima sehingga dapat merangsang perasaan, perhatian dan pikiran anak didik untuk tercapainya suatu tujuan pendidikan [5]. Mendekripsikan media sebagai saluran komunikasi. Istilah media itu berasal dari bahasa Latin dan merupakan bentuk jamak dari kata "medium" yang secara harfiah berarti "perantara" yaitu perantara sumber pesan dengan penerima pesan.

Dalam kegiatan pembelajaran terdapat proses komunikasi yaitu guru bertindak sebagai komunikator yang bertugas untuk menyampaikan pesan pendidikan kepada penerima pesan yaitu anak.

\subsection{Pemodelan Sistem}

Pemodelan sistem adalah proses merancang suatu piranti lunak sebelum melakukan pengkodean. Model piranti lunak dapat dibuat seperti membuatan blueprint pada pembuatan bangunan. Membuat contoh dari sebuah sistem yang tepat sangatlah penting, karena kita belum dapat memahami sistem itu secara keseluruhan. Semakin canggih suatu sistem, maka semakin canggih pula penggunaan suatu teknik pemodelan. Dengan menggunakan suatu model, pengembangan piranti lunak dapat mengakses semua keperluan pengguna dengan tepat dan lengkap, termasuk faktor-faktor seperti security, scalability, robustness dan lain sebagainya.

Unified Modeling Language adalah bahasa dari suatu grafis untuk menspesifikasikan, mendokumentasikan, dan membangun suatu model sebuah sistem pada perangkat lunak. Unified Modeling Language adalah berorientasi, menerapkan banyak level abstraksi, yang bergantung pada sebuah objek 
yang diproses melalui pengembangan desain

teknologi, penggabungan dari notasi yang beragam, usaha ini didukung oleh kakas yang disalurkan melalui Standar Unified Modeling Language yang dikelola dengan Object Management Group. Unified Modeling Language merupakan suatu bahasa pemodelan untuk menspesifikasikan, membangun, dan mendokumentasikan sebuah sistem. Konsep yang akan diterapkan di Unified Modeling Language yaitu satu model berisi informasi mengenai sebuah sistem atau domain, dan model berisi tentang elemen seperti paket-paket, kelaskelas simpul-simpul, dan masih banyak yang lainnya. Satu diagram menunjukkan satu pandangan tertentu dari sebuah model [6].

\subsection{Android}

Android merupakan suatu sistem untuk telepon pintar dengan sistem berbasis linux yang dirancang untuk perangkat layar sentuh, Android mempersiapkan platform yang dipergunakan bagi developer untuk membuat apikasi yang dibuat sendiri untuk bisa dipergunakan diberbagai situasi bergerak. Pada pengembangan android dibuat sebuah tim yang diberi nama Open Handset Alliance, merupakan 34 perusahaan telekomunikasi, piranti lunak dan piranti keras diantaranya adalah Nvidia, Qualcom, Corola, Intel, HTC, Google [7].

\subsection{Web Service}

Web service merupakan sebuah sistem perangkat lunak yang merancang sebagai pendukung interaksi antara suatu sistem dengan suatu jaringan. Web service digunakan untuk suatu fasilitas yang dipersiapkan oleh website yang menyediakan pelayanan kepada sistem lain, sehingga membuat sistem lain dapat berinteraksi dengan sistem tersebut dengan melalui pelayanan yang dipersiapkan oleh sebuah sistem yang menyediakan web service. Web service akan mempersiapkan data informasi dalam format $\mathrm{XML}$, sehingga nantinya data ini bisa diakses oleh sistem lain walaupun berbeda pada platform, sistem operasi [8].

\section{METODOLOGI PENELITIAN}

\subsection{Tahapan Penelitian}

Pada tahap penelitian ini pengembangan Rancang Bangun Aplikasi Media Pembelajaran Pengenalan Rupa dan Karakter Tokoh Wayang Purwa menggunakan Multi- yang tidak bergantung pada suatu bahasa dan

media Development Life Cycle yang terdiri dari beberapa tahapan sebagai berikut :

a. Konsep: Merencanakan dasar dari proyek multimedia yang akan dirancang dan dikembangkan

b. Perancangan: Tahapan ini adalah ketika pembuatan atau perancangan proyek multimedia dijabarkan secara rinci yang akan dilakukan dan bagaimana rancangan multimedia tersebut akan dilakukan. Pembutan naskah atau navigasi serta proses perancangan desain lain harus dibuat secara lengkap. Ditahapan ini harus mengetahui bagaimana hasil akhir dari proyek yang dikerjakan.

c. Pengumpulan Materi: Pada pengumpulan materi ini adalah mengumpulkan segala materi yang akan diperlukan dalam proyek yaitu file multimedia seperti gambar, audio dan video yang akan dipresentasikan kedalam proses penyajian multimedia.

d. Pembuatan dan penyusunan: Pada saat penyusunan dan pembuatan multimedia, untuk mendapatkan proses ini dibutuhkan materi serta file-file multimedia yang kemudian disusun dan digabungkan sesuai disain yang harus membutuhkan kemampuan para ahli untuk mendapatkan hasil yang sempurna.

e. Pengujian: Saat multimedia telah selesai, hal yang harus diperlukan yaitu adanya pengujian dengan menggunakan hasil data dan proyek multimedia pada pembelajaran. Hal ini agar multimedia yang sebelumnya dibuat memang benar dan sesuai,agar nantinya dapat diterapkan menjadi pembelajaran secara keseluruhan.

f. Penyebaran: Pada saat tahap penyebaran dapat dilakukan dengan cara melalui CD/DVD, download ataupun dengan media yang lain kepada pengguna

\subsection{Gambaran Umum Sistem}

Gambaran umum sistem adalah gambaran proses yang dijelaskan secara keseluruhan dari jalannya aplikasi ini serta menjelaskan tentang modul apa saja yang nantinya akan dijelaskan dalam pembuatan aplikasi. Pada Gambar 1 dapat dilihat bahwa terdapat dua user utama yaitu Administrator dan Android. Administrator memiliki tugas untuk memaintenance data wayang purwa pada client Aplikasi Wayang Purwa, dan bertugas juga untuk menambahkan data, mengedit data, meng-upload gambar wayang purwa. Sedangkan peng- 
guna pada aplikasi dapat menjalankan aplikasi dan data yang terkait wayang purwa yang di- akses dari web server aplikasi wayang purwa.

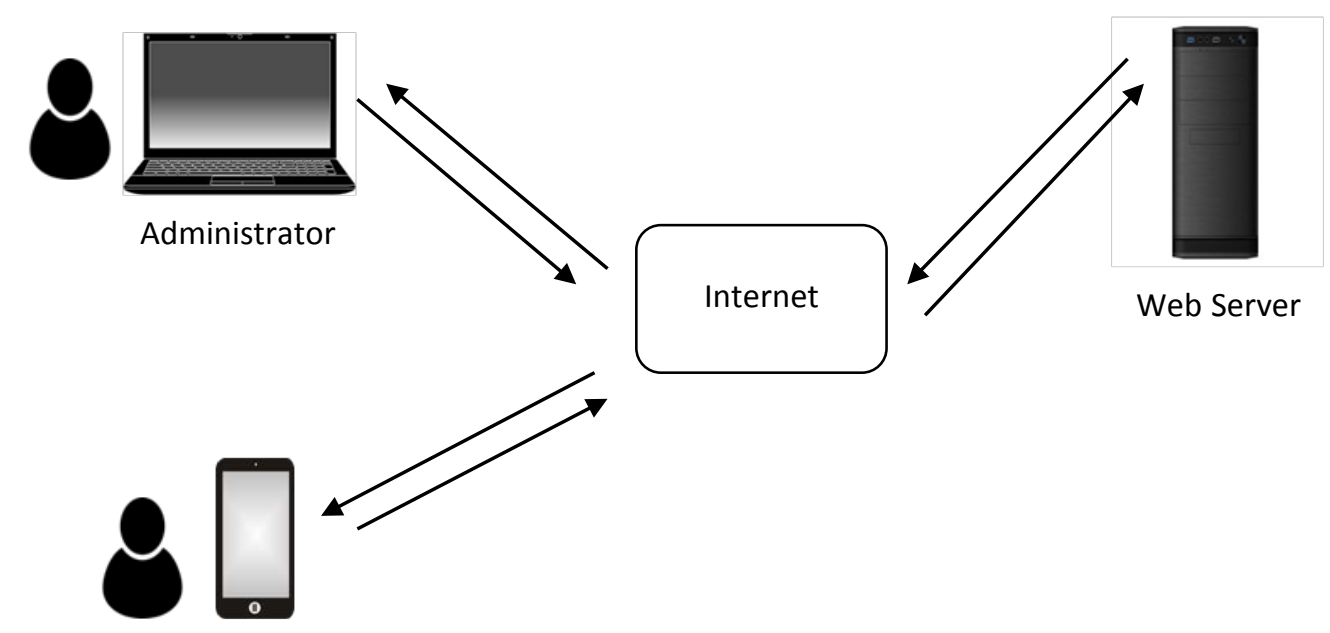

User Aplikasi Wayang Purwa

Gambar 1. Gambaran Umum Sistem

\subsection{Perancangan Sistem}

\subsubsection{Use Case Diagram}

Pada Diagram Use Case dari aplikasi wayang purwa menjelaskan tentang proses interaksi antara user aplikasi dengan sistem, dimana user aplikasi dapat mengakses menu dari aplikasi wayang purwa yaitu, wayang pur- wa, quiz, help, dan about. Sedangkan administrator dapat memperbaiki kekurangan dari aplikasi wayang purwa yaitu, tambah wayang purwa, edit wayang purwa, dan hapus wayang purwa. Use case diagram dari Aplikasi Wayang Purwa adalah sebagai berikut dapat dilihat pada Gambar 2.

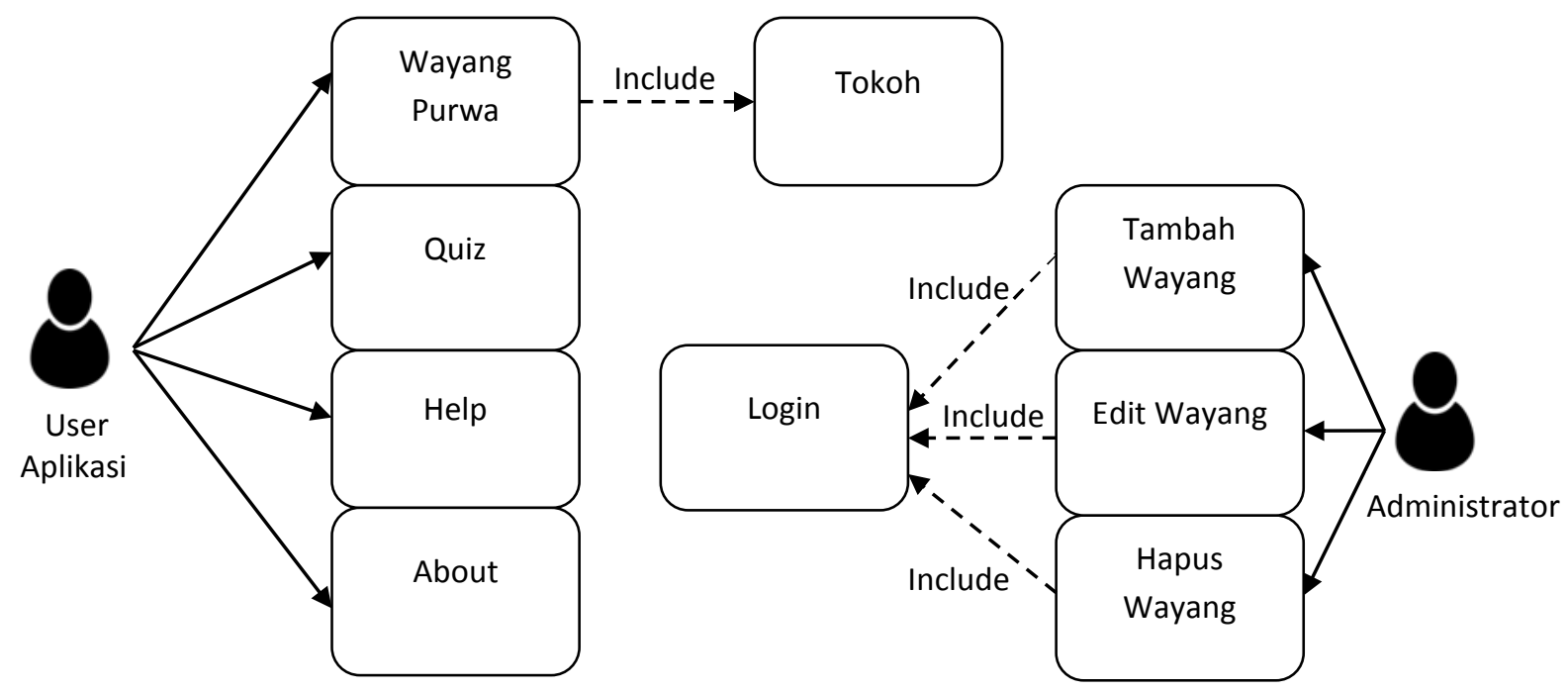

Gambar 2. Use Case Diagram

\subsubsection{Class Diagram}

Class Diagram adalah sebuah spesifikasi yang jika diinstansikan akan menghasilkan sebuah objek dan merupakan inti dari pengembangan dan desain berorientasi objek. Class menggambarkan keadaan (atribut/property) suatu sistem sekaligus menawarkan layanan untuk memanipulasi keadaan tersebut (metoda/fungsi). Class diagram menggambarkan struktur dan deskripsi class, package, objek 
beserta hubungan satu sama lain seperti constraint, pewarisan, association, dan lain-lain. Pada class main menu mempunyai association dengan class help, about, quiz, wa- yang purwa. Class wayang purwa mempunyai association dengan class list tokoh. Class diagram dari Aplikasi Wayang Purwa adalah sebagai berikut dapat dilihat pada Gambar 3 .

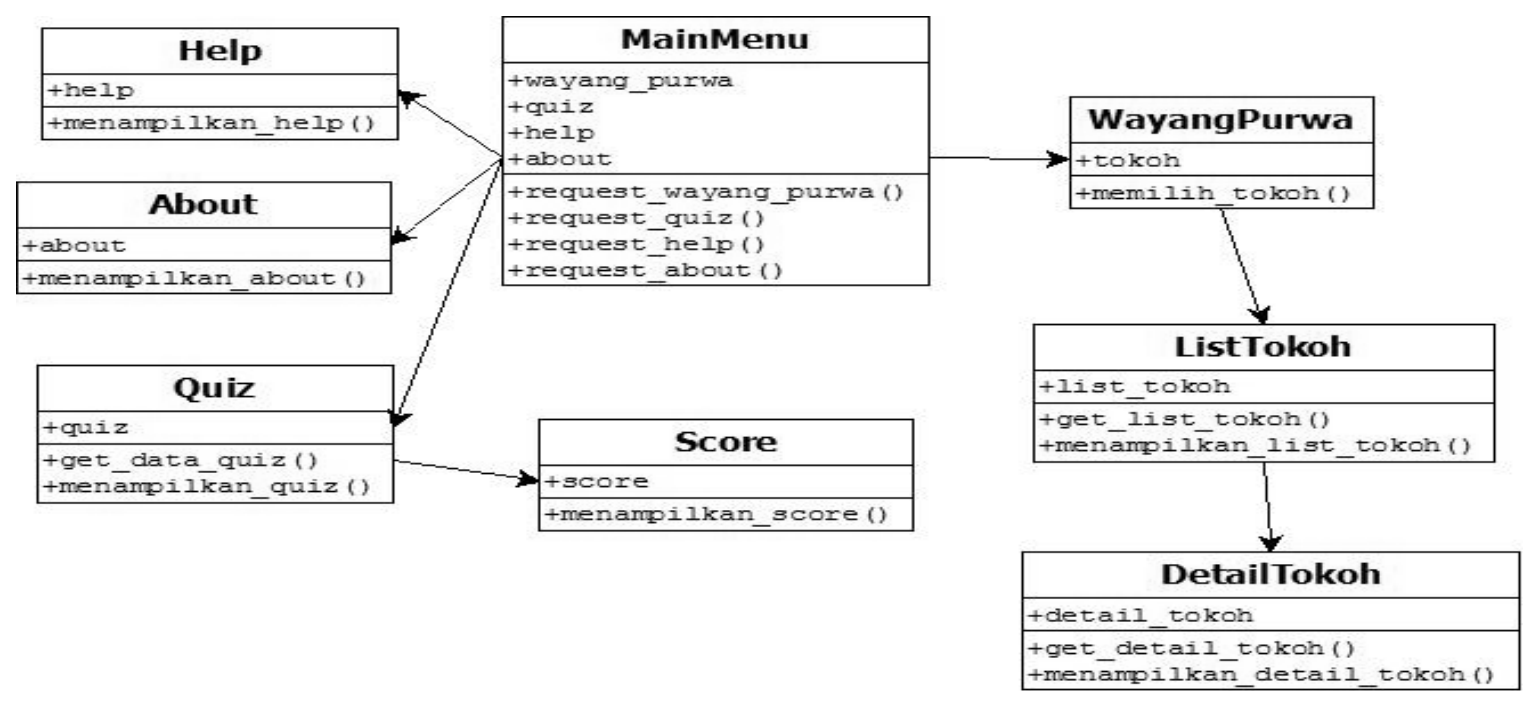

Gambar 3. Class Diagram

\subsubsection{Perancangan Data Base}

Pada perancangan data base terdapat Relasi Antar Tabel wayang purwa dan user memliki relasi. Misalnya Wayang_Purwa memiliki id_wayang_purwa nama, keterangan, gambar, id_user. Setiap Wayang_Purwa terhubung dengan user. User memiliki id_user, username, password. Penjelasan relasi antar tabel dapat dilihat pada Gambar 4.

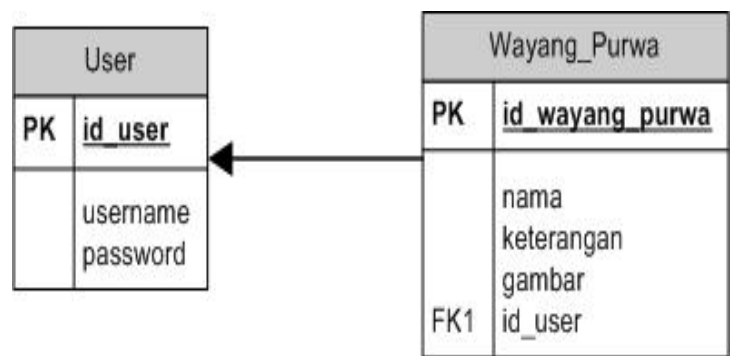

Gambar 4. Relasi Antar Tabel

\section{HASIL DAN PEMBAHASAN}

\subsection{Hasil}

Dalam pembuatan Aplikasi Wayang Purwa dihasilkan dua buah aplikasi yaitu aplikasi server yang berfungsi untuk menyimpan datadata gambar maupun penjelasan dari masingmasing karakter wayang dan aplikasi client yang berbasis Android yang berfungsi untuk menampilkan permainan wayang purwa itu sendiri, berikut penjelasannya:

\section{a. Aplikasi Server}

Aplikasi Server ini menggunakan apache server sebagai webserver-nya dan mySQL sebagai basis datanya. Aplikasi server yang digunakan dalam Aplikasi Wayang Purwa ini berbasis Single Page Application yang berbasis javascript menggunakan framework angularjs.

b. Aplikasi Client

Aplikasi Client berfungsi untuk menampilkan data-data wayang purwa yang disimpan di server. Data-data pembuatan aplikasi client ini menggunakan Unity $3 D$ untuk membuat logic permainannya dan untuk pembuatan gambar menggunakan aplikasi Adobe Illustrator dan Adobe Photoshop.

\subsection{Pembahasan}

Dalam pembahasan berikut ini akan dibahas tentang tampilan yang ada pada Aplikasi Wayang Purwa sebagai berikut.

\subsubsection{Tampilan Web Admin}

a. Login

Pada saat membuka halaman web Aplikasi wayang Purwa maka pertama kali yang dimunculkan adalah halaman login dengan 
username adalah admin dan password yang dapat dilihat pada Gambar 5.

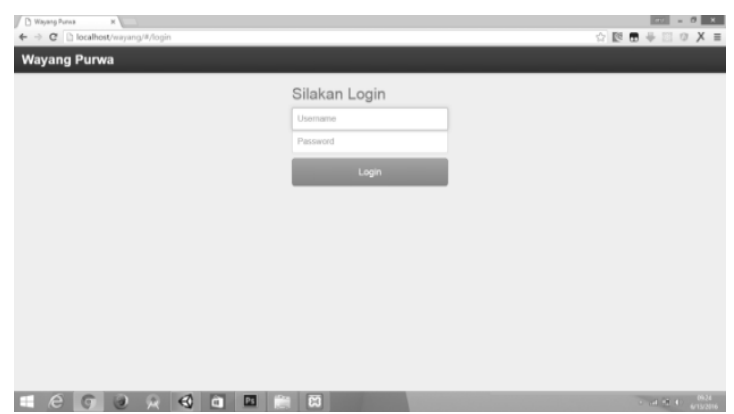

\section{b. List Wayang Purwa}

Pada halaman ini terdapat tombol tambah untuk menambah data wayang purwa dan juga terdapat tombol edit untuk mengedit data wayang purwa, tombol hapus untuk menghapus data wayang purwa dan juga tombol upload untuk mengupload gambar wayang purwa. Berikut ini adalah tampilan dari List Wayang Purwa dapat dilihat pada Gambar 6.

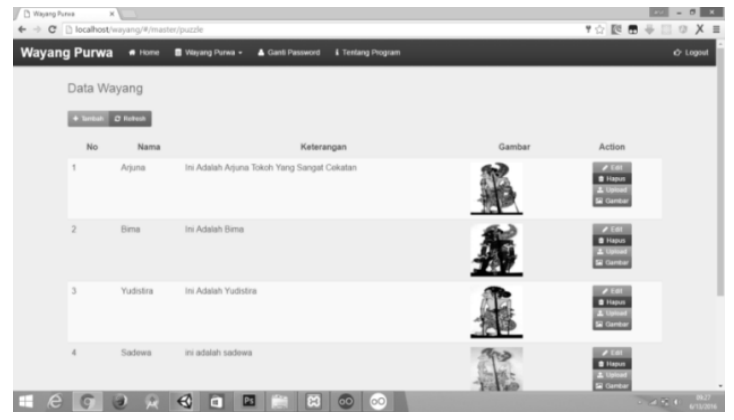

Gambar 6. Halaman List Wayang

\section{c Tambah Wayang Purwa}

Pada halaman ini berisi field nama untuk mengisi nama wayang purwa yang akan di tampilkan dan keterangan untuk mengisi keterangan dari wayang purwa itu sendiri. Berikut ini gambaran dari halaman Tambah Wayang Purwa dapat dilihat pada Gambar 7.

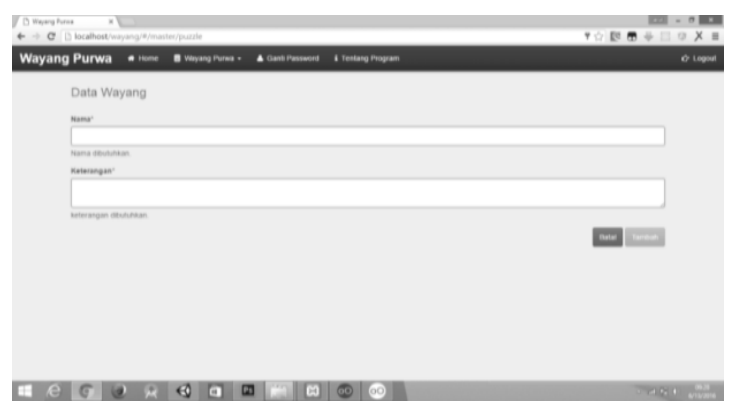

Gambar 7. Halaman Tambah Wayang Purwa
Gambar 5. Admin Login Wayang Purwa

\subsubsection{Tampilan Aplikasi Android Wayang Purwa}

\section{a. Halaman Utama}

Pada halaman utama terdapat tombol wayang purwa yang berfungsi untuk mengetahui penjelasan dari wayang purwa, tombol Puzzle yang berfungsi untuk memainkan permainan puzzle, tombol quiz untuk menebak gambar wayang purwa, tombol keluar berfungsi untuk keluar dari aplikasi wayang purwa, tombol dengan gambar setting berfungsi untuk ke halaman setting, tombol dengan gambar info yang berfungsi untuk ke halaman about. Berikut ini adalah gambaran dari menu utama Aplikasi Wayang purwa yang dapat dilihat pada Gambar 8.

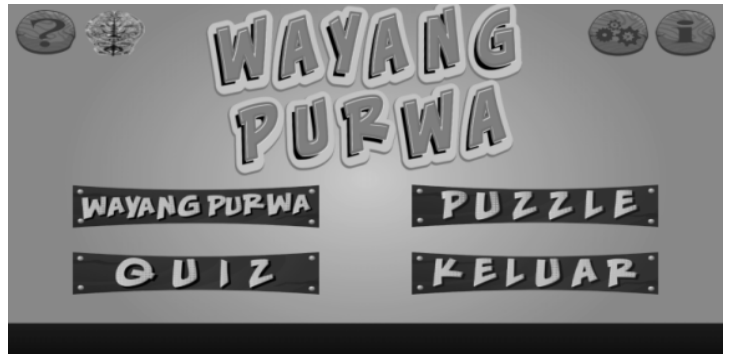

Gambar 8. Halaman Menu Utama Aplikasi Wayang Purwa

\section{b. Halaman Puzzle}

Pada halaman ini merupakan gambaran dari permainan drag and drop Aplikasi Wayang Purwa. User harus memindahkan potongan gambar ke dalam gambar tanda tanya sampai tersusun gambar utuh.berikut adalah gambaran dari permainan drag and drop yang dapat dilihat pada Gambar 9. 


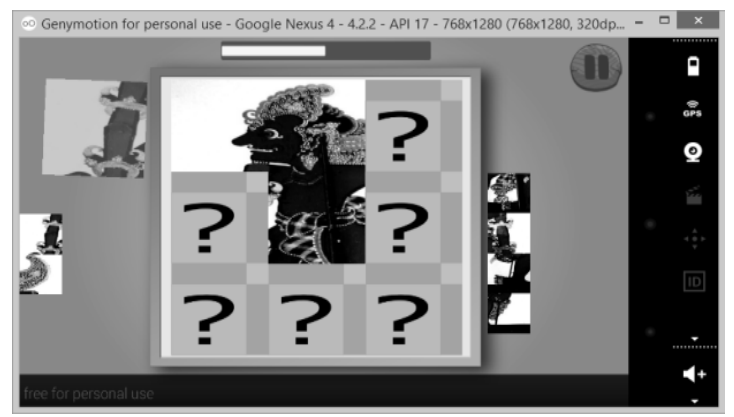

Gambar 9. Halaman Puzzle Aplikasi Wayang Purwa

\section{c. Halaman Info Wayang Purwa}

Pada halaman info wayang purwa ini muncul ketika user menklik tombol info pada dialog success. Halaman ini berisi keterangan dari gambar wayang purwa yang telah user selesai mainkan. Berikut ini adalah gambaran dari halaman info wayang purwa yag dapat dilihat pada Gambar 10.

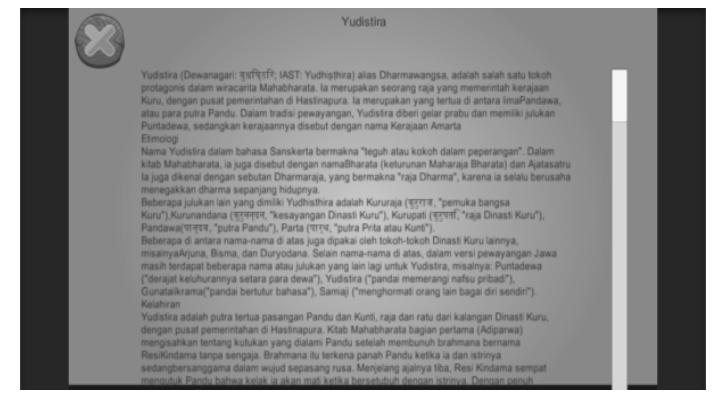

Gambar 10. Halaman Info Wayang Purwa Aplikasi Wayang Purwa

\section{d. Halaman Quiz}

Pada halaman ini user harus menebak gambar, jika user berhasil menebak gambar maka akan mendapatkan score 10 jika waktu habis atau user salah menebak maka akan mendapatkan nilai nol. Berikut ini adalah gambaran dari halaman quiz wayang purwa yag dapat dilihat pada Gambar 10.

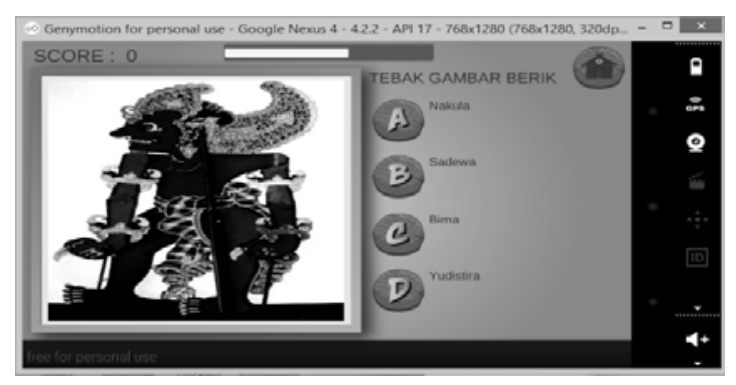

Gambar 11. Halaman Quiz Wayang Purwa Aplikasi Wayang Purwa
Pengujian terhadap aplikasi dilakukan melalui tiga tahapan yaitu :

1. Pengujian Black Box

Pengujian yang dilakukan terhadap Aplikasi Wayang Purwa ini berfokus pada persyaratan fungsional perangkat lunak dimana seluruh fungsionalitas perangkat lunak dapat berjalan dengan baik dan lancar.

2. Pengujian pada Device

Disini ada beberapa jenis smartphone yang digunakan yaitu Samsung Galaxy Tab 3, Asus Selfi dan Xiaomi Mi 4i dan aplikasi dapat berjalan dengan baik pada semua perangkat uji.

3. Usability Testing

Berdasarkan hasil pengujian usability testing, memanfaatkan kuisioner terhadap 30 responden diperoleh hasil pada pengujian aspek grafis visual sebanyak $57 \%$ responden memberikan respon baik sedangkan pada pengujian aspek entertaintment dan pembelajaran sebanyak 90\% responden memberikan respon baik.

\section{SIMPULAN}

Simpulan yang dapat diambil dari Aplikasi Wayang Purwa berbasis Android yaitu :

1. Aplikasi Wayang Purwa di buat dengan menggunakan metode Multimedia Development Life Cycle dengan Software Adobe Photoshop dan Adobe Illustartor untuk designdan Software Unity 5.2.0 untuk assembly serta diinstal pada smartphone berbasis Android untuk testing.

2. Aplikasi Wayang Purwa ini memiliki tampilan antar muka yang menarik serta memberikan pengetahuan terhadap generasi muda.

3. Aplikasi ini dapat berjalan dengan baik pada smartphone yang memiliki detail minimal :
a. Operasi sistem Android 4.1 (Jelly Bean)
b. CPU Dual-core $1.7 \mathrm{GHz}$
c. GPU Adreno 305 (GPU kelas mid- end)
d. Random Acces Memory 1,5 GB
e. Resolusi layar $720 \times 1280$ pixels, 5.0 inchi
Berdasarkan hasil pengujian BlackBox Aplikasi Wayang Purwa ini berjalan sesuai dengan fungsinya.

\section{DAFTAR PUSTAKA}

\section{PENGUJIAN}


[1] "Rifai, W. A. 2015. 'Pengembangan Game Edukasi Lingkungan Berbasis Android' (Tugas Akhir). Yogyakarta: Universitas Negeri Yogyakarta.," n.d.

[2] "Puspita, K. C. 2010. 'Rancang Bangun Aplikasi Game "Puzzle Kata"' (Tugas Akhir). Yogyakarta: Universitas PGRI Yogyakarta.," n.d.

[3] "Nurdiah, P. S. F. 2010. 'Rancang Bangun Aplikasi Edukasi "Ceria" Berbasis Android Sebagai Media Pembelajaran Untuk Anak Usia Dini' (Tugas Akhir). Palembang: Universitas STMIK MDP.," n.d.

[4] "Josowidagdo, R. T. 2013. http://aninditawikanti.blogspot.co.id/2013/01/me- ngenal-wayang-lebih-jauh-pengertian.html. Diakses tanggal 12 Januari 2016.," n.d.

[5] "Trianto. 2009. Mendesain Model Pembelajaran Inovatif-Progresif. Jakarta : Kencana.," n.d.

[6] "Sismoro, H. 2005. Pengantar Logika Informatika, Algoritma Dan Pemrograman Komputer.Yogyakarta : Andi Offset.," n.d.

[7] "Elcom. 2012. Exploring Android On Your Own PC. Yogyakarta: Andi.," n.d.

[8] "Hasril, H. T. 2004. Kamus Komputer Untuk Orang Awam Cetakan 1. Palembang : Maxiko," n.d. 